\title{
A case of quadricuspid aortic valve characterized by echocardiography and magnetic resonance imaging
}

\section{Un caso di valvola aortica quadricuspide valutato tramite ecocardiogramma e Risonanza magnetica}

\author{
Achille Pulcino1, Chiara Sordelli1, Gennaro Ismeno1, Francesco Paolo Tritto1, \\ Paolo Golino2, Luigi Piazza1
}

\begin{abstract}
A case of quadricuspid aortic valve characterized by echocardiography and magnetic resonance imaging. A. Pulcino, C. Sordelli, G. Ismeno, F.P. Tritto, P. Golino, L. Piazza.

We report a rare subtype of quadricuspid aortic valve (QAV) associated with moderate aortic regurgitation in a 17year old woman symptomatic for palpitations. The patient was admitted to our department for cardiac evaluation due to a previous diagnosis of bicuspid aortic valve; she underwent a new two-dimensional echocardiography revealing a rare type of quadricuspid aortic valve with a moderate regurgitation. For further investigating potentially associated abnormalities,
\end{abstract}

\begin{abstract}
patient was referred to Cardiac MRI; MRI showed no other abnormalities and confirmed echocardiographic findings. Quadricuspid aortic valve is a rare form of congenital valvular anomaly often occasionally diagnosed. In most cases this malformation causes a valve dysfunction, commonly aortic regurgitation, and can be associated with other cardiac abnormalities such as ventricular or atrial septal defect, anomalies of coronary arteries, patent ductus arteriosus, subaortic fibromuscolar stenosis and mitral valve malformation.
\end{abstract}

Monaldi Arch Chest Dis 2011; 76: 146-148.

1 Department of Cardiac Surgery, S. Anna e S. Sebastiano Hospital, Caserta, Italy.
2 Department of Cardiothoracic Sciences, Monaldi Hospital, Second University of Naples, Italy.

Corresponding author: Chiara Sordelli; Viale della Gioventù, 12; I-80059 Torre del Greco (NA), Italy; Phone: 0818494651; Mobile phone: 3403960638

\section{Introduction}

Quadricuspid aortic valve (QAV) is a rare variant of aortic valve morphology and only few cases have been reported since its initial description. The impact of this condition on aortic valve function is unclear, although QAV has been frequently associated with aortic regurgitation, while valvular stenosis is uncommon. QAV has been described in isolation as well as in association with other cardiac abnormalities such as ventricular or atrial septal defect, anomalies of coronary arteries, patent ductus arteriosus, subaortic fibromuscolar stenosis and mitral valve malformation [1-2].

\section{Case Report Presentation}

A 17-year old girl with a previous diagnosis of bicuspid aortic valve was admitted to our Department for a routine cardiac evaluation. Her medical history was not significant, except for a $\beta$-thalassemic trait. At admission she complained about recent episodes of palpitations, while there was no history of syncope, chest pain and/or reduced exercise capacity. On physical examination her systemic blood pressure was $120 / 60 \mathrm{mmHg}$, with an heart rate of $80 \mathrm{bpm}$ and a diastolic murmur was audible over the left sternal border. Chest X-ray was normal. The ECG showed normal sinus rhythm and a 24h Holter ECG monitoring revealed few isolated ventricular ectopic beats.
Two-dimensional transthoracic echocardiography showed preserved left ventricular diameters with normal systolic function (ejection fraction = 57\%). On parasternal short-axis views an atypical morphology of the aortic valve was observed. On diastole, the cusps closure assumed a X-shaped instead of the usual Y-shaped appearance (fig. 1).

In the systolic frame the valve showed an almost perfect round opening, clearly different from the elliptical opening of the classic functional bicuspid aortic valve (fig. 1). The valve consisted of four cusps: one large cusp, two intermediate-sized cusps and one smaller cusp (QAV; type D in the Hurvitz and Roberts classification). Doppler examination demonstrated a central jet with moderate aortic regurgitation resulting from incomplete diastolic cusp coaptation. The size of thoracic aorta was within normal range. Cardiac magnetic resonance imaging (MRI) confirmed the diagnosis of QAV, excluding other associated abnormalities (fig. 1).

\section{Discussion}

QAV is a rare form of congenital valvular anomaly often discovered occasionally during autopsy, echocardiography, angiography or surgery [1-3]. Its incidence ranges from 0.003 to $0.043 \%$ as reported in the literature [4]. Transthoracic echocardiography plays an important role in the assessment of this anomaly although transesophageal echocardiogra- 


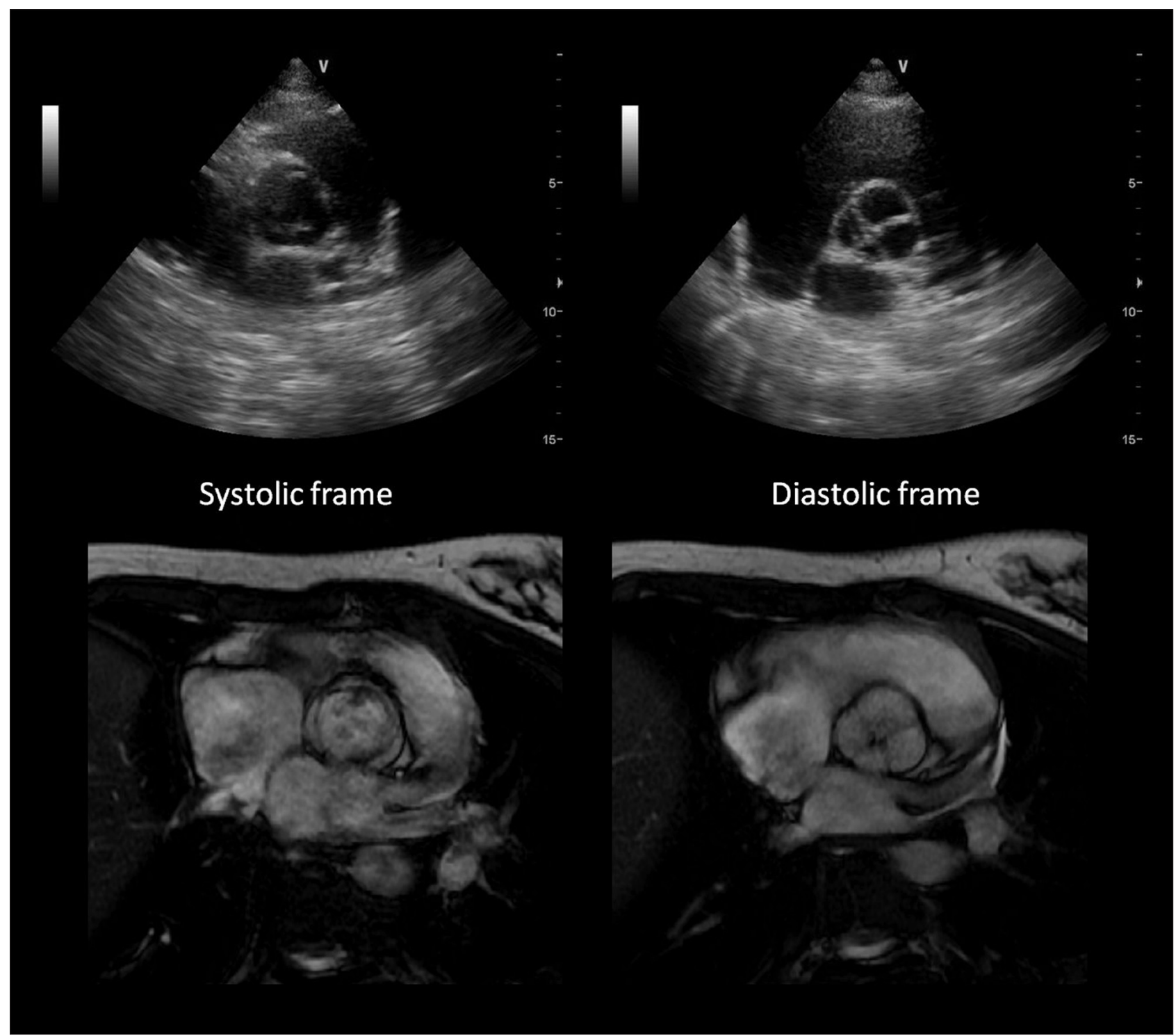

Figure 1. - Echocardiograpic and MRI images showing quadricuspid aortic valve with one large, two intermediate and one small cusp.

phy and cardiac MRI can give additional important information. QAV may be found as an isolated lesion or in association with other cardiac congenital anomalies [4-5]. Aortic regurgitation is the predominant valvular dysfunction and generally results from cusp malcoaptation [1-4]. According to the cusp size Hurvitz and Roberts proposed a classification in 7 subtypes [3-6]:

A. Four equal-sized cusps

B. Three equal-sized cusps and one smaller

C. Two larger and two smaller cusps

D. One large cusp, 2 intermediate-sized cusps and 1 smaller cusp

E. Three equal-sized cusps and one larger

F. Two equal and two unequal smaller cusps

G. Four unequal cusps.

The most common type is B, followed by Type A [6]. Type D, as the one we described here, is a very rare valvular anomaly; as showed, the presence of an additional smaller cusp can result in cusp malcoaptation during diastole causing regurgitation [1]. In our case transthoracic echocardiography was sufficient to clarify valvular anatomy but cardiac MRI was helpful in confirming the diagnosis and excluding associated abnormalities.
In conclusion, QAV is a rare form of congenital valvular anomaly and in this case we have described by transthoracic echocardiography and cardiac MRI a very rare subtype of this anomaly associated with a moderate aortic regurgitation.

\section{Riassunto}

Si descrive un raro subtipo di valvola aortica quadricuspide (QAV) associate a insufficienza valvolare aortica moderata in una paziente di 17 anni sintomatica per palpitazioni. La paziente venne alla nostra osservazione con una diagnosi di valvola aortica bicuspide; ad un nuovo esame ecocardiografico si evidenziò un raro tipo di quadricuspidia della valvola aortica con insufficienza valvolare moderata. Alla ricerca di possibili anomalie associate, fu sottoposta a Risonanza Magnetica Cardiaca: l'indagine non evidenziò altre anomalie e confermò la diagnosi ecocardiografica. La quadricuspidia della valvola aortica è una rara anomalia congenita spesso diagnosticata occasionalmente. Nella gran parte dei casi provoca una disfunzione valvolare, e può essere associata ad altre anomalie, come difetto del setto interatriale o ventricolare, anomalie coronariche, dot- 
to arterioso pervio, stenosi fibromuscolare sottoaortica o malfunzione mitralica.

\section{References}

1. D'Aloia A, Vizzardi E, Bugatti S, et al. A quadricuspid aortic valve associated with severe aortic regurgitation and left ventricular systolic dysfunction. Eur J Echocardiogr 2009; 10: 724-5.

2. Youn YJ, Kim JY, Harn SW, et al. A case of quadricuspid aortic valve with aortic regurgitation. J Cardiovasc Ultrasound 2010; 18: 70-1.
3. Xiao Z, Meng W, Zhang E. Quadricuspid aortic valve by using intraoperative transesophageal echocardiography. Cardiovasc Ultrasound 2010; 8: 36.

4. Zacharaki AA, Patrianakos AP, Parthenakis FI, Vardas PE. Quadricuspid aortic valve associated with non-obstructive sub-aortic membrane: a case report and review of the literature. Hellenic J Cardiol 2009; 50: 544-7.

5. Armen TA, Vandse R, Bickle K, Nathan N. Three-dimensional echocardiographic evaluation of an incidental quadricuspid aortic valve. Eur J Echocardiogr 2008 Mar; 9: 318-20.

6. Hurwitz LE, Roberts WC. Quadricuspid semilunar valve. Am J Cardiol 1973; 31: 623-626. 